\title{
Kostik madde içimi sonrası gastrointestinal darlık gelişen hastalarda endoskopi tecrübemiz
}

\section{Experience of endoscopy in patients with gastrointestinal stenosis after caustic ingestion}

(D) Mustafa KAPLAN ${ }^{1}$, (D) Bülent ÖDEMIŞ², (D) Selçuk DişiBEYAZ³ , (D) Erkan PARLAK ${ }^{4}$, (D Volkan GÖKBULUT²,

(D) Adem AKSOY', (D) Orhan COşKUN² , (D) Muhammet Yener AKPINAR²

Ahi Evran Üniversitesi Eğitim ve Araşstırma Hastanesi, ${ }^{1}$ Gastroenteroloji Kliniği, Kırşehir

Türkiye Yüksek Ihtisas Eğitim ve Araștırma Hastanesi, ${ }^{2}$ Gastroenteroloji Kliniği, Ankara

Osmangazi Universitesi Tip Fakültesi, ${ }^{3}$ Gastroenteroloji Bilim Dal, Eskişshir

Hacettepe Universitesi Tip Fakültesi, ${ }^{4}$ Gastroenteroloji Bilim Dall, Ankara

\begin{abstract}
Giriş ve Amaç: Bu çalı̧̧mada gastrointestinal kostik yaralanma sonrası endoskopik tedavi uygulanan hastaların etiyolojik nedenlerini, darlik yerlerini ve uygulanan tedavileri araştırdık. Gereç ve Yöntem: Bu çalışma 2005-2015 yılları arasında kostik hasara bağlı darlık nedeniyle endoskopik olarak tedavi edilen 41 hasta ile retrospektif olarak yapılmıştır. Hastaların demografik özellikleri, ameliyat bilgileri, ne içtikleri ve darlık yerleri dosyalarından kaydedilmiştir. Bulgular: Bu çalışma 41 hasta ile yapılmıştır. Hastaların ortalama yaşı $32 \pm 9.2$ idi. Hastaların 25'i erkek (\%61), 16'sı ise kadındı (\%39). Hastalarnn median işlem sayısı 9 olup, işlem sayısı 1 ile 32 arasında değişmekteydi. Kostik hasarın en sık sebebi ozon suyu (\%19), yağ çözücü (\%15) ve kirę̧ çözücü (\%15) idi. Endoskopik incelemede darlıklar en sık orta özofagusta (\%41) görülmekle birlikte daha az siklikla proksimal özofagus (\%19), distal özofagus (\%19), anastomoz (\%10) ve tüm özofagusta (\%7) görülmekteydi. 6 hastanın darlıklar nedeniyle opere edildiği görüldü (\%15). Hastalara yapılan terapötik işlemler incelendiğinde en sık buji ve balon dilatasyonu uygulandığı görüldü. Iki hastaya lokal steroid enjeksiyonu ve iki hastaya da stent takıldığı görüldü. Sonuç: Kostik madde içimine bağlı özofagus darlığı en sık olarak temizlik maddelerinin içimine bağlı olarak gelişmekte, en sık özofagus orta kısminı tutmakta ve tedavide en sik balon ve buji dilatasyon tedavisi kullanılmaktadır.
\end{abstract}

Anahtar kelimeler: Özofagus darlıkları, Savary-Gilliard dilatasyonu, balon dilatasyonu

\section{GİRISS}

Asit veya alkali kostik maddelerin yutulması yemek borusu ve midede ciddi yaralanmalara neden olabilir (1). Çocuklarda daha çok kazara içme söz konusu iken yetişkinlerde intihar amaçlı ve psikiyatrik rahatsızlık sonucu içme daha sık olarak görülmektedir (2,3). Kostik madde içen hastaların birçoğu depresyon, şizofreni, uyum sorunları ve kişilik bozuklukları gibi eşlik eden psikiyatrik bozukluklara sahiptir (4). Ortaya çıkan yaralanma ve darlık, önemsizden hayatı tehdit edecek duruma kadar değişiklik gösterebilir. Yaralanma derecesi, maddenin yapısına (korozyona neden olabileceği dereceye), tüketilen miktara, konsantrasyonuna, durumuna (katı veya SIv1) ve gastrointestinal (GI) mukozayla temas zamanına göre belirlenir (5). Özellikle intihara teşebbüs eden kişilerde çok miktarda madde yutulursa, yemek borusu ve midede daha ciddi yaralanmalar meydana gelir (6). Geçmişle karşılaştırıl-
Background and Aims: This study investigated the etiologic causes, stenosis locations, and endoscopic treatment options of caustic gastrointestinal injury. Material and Methods: This study was performed retrospectively, with 41 patients who were treated endoscopically for stenosis caused by caustic damage between 2005 and 2015. Datas such as patients' demographic characteristics, surgical information, ingested material, and stenosis locations were obtained from their medical records. Results: This study comprised 41 patients. The mean age of patients was $32 \pm 9.2$ years. Of these, 25 patients were males (61\%), and 16 were females (39\%). The median number of endoscopy procedures was 9 and ranged from 1 to 32. The most common causes of caustic damage were ozone water (19\%), degreasers (15\%), and descaling agents (15\%). Endoscopic examination revealed stenosis most frequently in the middle esophagus (41\%), but less frequently in the proximal esophagus (19\%), distal esophagus (19\%), anastomosis (10\%), and the entire esophagus (7\%). Six patients were operated for strictures (15\%). Savary-Gilliard and balloon dilatation were the most frequently applied treatments. Two patients had local steroid injections, and two had stents. Conclusion: Esophageal stenosis because of caustic ingestion develops most frequently by ingesting cleaning agents and most commonly involves the middle part of the esophagus, and balloon and Savary-Gilliard dilatation are most commonly used treatment options.

Keywords: Esophageal stenoses, Savary-Gilliard dilatation, balloon dilatation

dığında sayılar azalmış olsa da, kostik madde içip acil servise gelen vakalar nadir değildir. Bu nedenle, bu çalışmada gastrointestinal kostik yaralanma sonrası endoskopik tedavi uygulanan hastaların etiyolojik nedenlerini, darlık yerlerini ve uygulanan tedavileri araştırdık.

\section{GEREÇ ve YÖNTEM}

Bu çalışma 2005-2015 ylları arasında hastanemiz gastroenteroloji kliniğinde kostik hasara bağlı darlık nedeniyle endoskopik olarak tedavi edilen 41 hasta ile retrospektif olarak yapılmıştır. Hastaların demografik özellikleri ve ameliyat bilgileri dosyalarından kaydedilmiştir. Özellikle hastaların ne içtiği dosyalarından araştırılmış, bazı hastaların etiyolojik faktörleri bulunamamıștır, ancak bu hastalar yine de çalışmaya dahil edilmiştir. Çalışmada bahsedilen ozon suyu yani çama- 
şır suyunun içinde alkali bir madde olan sodyum hipoklorit bulunmaktadır. Yağ çözücü ve kireç çözücüler ise asidiktir. Çalışmada özofagusta darlık yerleri proksimal (ilk $5 \mathrm{~cm}$ ), orta (ortadaki $20 \mathrm{~cm}$ ) ve distal (Z line'ın yukarısındaki 5 cm'lik kısım) olarak sınıflanmıştır. Tedavide balon veya buji dilatasyonu yapılan hastalar belirtilmiştir. Çalışmada tedavi amaçlı 5-15 mm boyutunda bujiler ve 10-30 mm boyutunda dilatasyon balonları kullanılmıştır. Tedavide yetersiz kalınan bazı hastalara lokal steroid enjeksiyonu uygulanmış veya stent takılmıştır. Steroid uygulanan hastalarda triamsinolon asetonid (40 mg/ml) $1 \mathrm{ml}, 2$ ml'ye seyreltilerek striktür bölgesinde 4 kadrana enjekte edildi. Tedavi yanıtsız hastalardan birisine $7 \mathrm{~cm}$ uzunluğunda, stent gövdesi $18 \mathrm{~mm}$ ve stent kenarı 22 mm olan tam kaplı self-expandabl metalik stent takıldı ve 6 hafta sonra çıkartıldı. Diğer bir hastaya ise $8 \mathrm{~cm}$ boyutunda, stent gövdesi $20 \mathrm{~mm}$ ve stent kenarı $25 \mathrm{~mm}$ olan biodegradabl stent takıldı. Bu hastaya üç ay sonra kontrol endoskopi yapıldı. Diğer uygulanan tedavilerin başarısı için hastaların takipleri incelenmiş ancak hastaların çoğunun tedavisi devam ettiği için tedavi başarısı çalışmada verilmemiştir.

İstatistiksel değerlendirme Statistical Package for Social Sciences (SPSS) for Windows 20 (IBM SPSS Inc., Chicago, IL) programı kullanılarak yapılmıştır. Verilerin normal dağılımı Kolmogorov-Smirnov testi ile değerlendirilmiştir. Sayısal değişkenlerden normal dağılım sergileyenler ortalama \pm standart sapma olarak, normal dağılım sergilemeyenler ortanca (min-maks) olarak gösterilmiştir. Kategorik değişkenler sayı ve yüzde olarak belirtilmiştir.

\section{BULGULAR}

Bu çalışma 2004-2015 yılları arasında kostik hasar nedeniyle endoskopik tedavi yapılan 41 hasta ile yapılmıştır. Hastaların

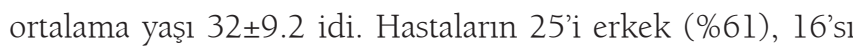
ise kadındı (\%39). 17 hastada (\%41) kostik hasarın sebebi bilinmezken 8 hastada ozon suyuna bağlı (\%19), 6 hastada yağ çözücüye bağlı (\%15), 6 hastada kireç çözücüye bağlı (\%15) ve iki hastada gübreye bağlı (\%5) kostik hasar oluşmuştu. Hastaları median işlem sayısı 9 olup işlem sayısı 1 ile 32 arasinda değişmekteydi. Endoskopik incelemede darlıklar en sık orta özofagusta (\%41) görülmekle birlikte daha az siklıkla proksimal özofagus (\%19), distal özofagus (\%19), anastomoz (\%10) ve tüm özofagusta (\%7) görülmekteydi. Bir hastada (\%2) hem distal özofagus hem de pilorda darlık saptandı. 6 hastanın darlıklar nedeniyle opere edildiği görüldü (\%15). 5 hastaya özofagojejunostomi yapilırken (\%13) bir hastaya gastrik-pull up operasyonu (\%2) yapılmıştı. Hastalara yapılan terapötik işlemler incelendiğinde en sık buji dilatasyonu uygulandığı görüldü (\%71). Balon dilatasyonu ise 10 hastaya uygulanmıştı (\%24). Iki hastaya balon ve buji dilatasyonu beraber uygulanmıştı (\%5). Lokal steroid injeksiyonu yapılan iki hastada (\%5) ise yanıt alınamadı. Ilki hastaya ise stent ko- nulmuştu (\%5). Bu hastalardan birinde darlığın düzelmediği görülürken biodegredabl stent takılan hastada darlığın düzeldiği görüldü. Diğer tedavi yöntemlerinin başarısı ise hasta takipsizliği ve işlemlerin devam etmesi nedeniyle tam olarak belirlenemedi. Çalışmamızda terapötik amaçlı cerrahi uygulanan 6 hastada operasyon öncesi maruz kaldığı kostik hasarın cerrahiye rağmen devam etmesine bağlı olarak tekrardan darlık gelişmişti. Bu hastalarda en sık darlık yeri anastomoz olmakla birlikte (4 hasta) bir hastada proksimal özofagusta, bir hastada ise distal özofagusta darlık saptandı. Hastaların demografik özellikleri, darlık yerleri, operasyon hikayeleri ve uygulanan tedaviler Tablo l'de verilmiştir.

\begin{tabular}{|c|c|}
\hline & $n=41(\%)$ \\
\hline Yaş & $32 \pm 9.2$ \\
\hline Cinsiyet (erkek/kadın) & $25(\% 61) / 16(\% 39)$ \\
\hline $\begin{array}{l}\text { Etiyoloji } \\
\text { Ozon suyu } \\
\text { Yağ çözücü } \\
\text { Kireç çözücü } \\
\text { Gübre } \\
\text { Bilinmeyen }\end{array}$ & $\begin{array}{c}8(\% 19) \\
6(\% 15) \\
6(\% 15) \\
2(\% 5) \\
17(\% 41)\end{array}$ \\
\hline Median seans sayısı & $9(1-32)$ \\
\hline $\begin{array}{l}\text { Darlık yeri } \\
\text { Tüm özofagus } \\
\text { Proksimal özofagus } \\
\text { Orta özofagus } \\
\text { Distal özofagus } \\
\text { Anastomoz } \\
\text { Distal özofagus ve pilor }\end{array}$ & $\begin{array}{l}3(\% 7) \\
8(\% 19) \\
17(41) \\
8(\% 19) \\
4(\% 10) \\
1(\% 2)\end{array}$ \\
\hline $\begin{array}{l}\text { Operasyon hikayesi } \\
\text { Özofagojejunostomi } \\
\text { Gastrik pull-up }\end{array}$ & $\begin{array}{c}6(\% 15) \\
5(\% 13) \\
1(\% 2)\end{array}$ \\
\hline \multicolumn{2}{|l|}{ Uygulanan tedaviler } \\
\hline Buji dilatasyonu & $29(\% 71)$ \\
\hline Balon dilatasyonu & $10(\% 24)$ \\
\hline Buji+balon dilatasyonu & $2(\% 5)$ \\
\hline Lokal steroid enjeksiyonu & $2(\% 5)$ \\
\hline Stent uygulanması & $2(\% 5)$ \\
\hline
\end{tabular}

\section{TARTISSMA}

Bu çalışmada kostik madde içimi sonrası gelişen darlıklar nedeniyle endoskopik tedavi yapılan hastaların demografik özellikleri, ameliyat tipleri ve uygulanan tedaviler incelenmiştir. Kostik darlıkların en çok orta özofagusu etkilediği, kostik darlık nedeniyle ameliyat yapılan hastalarda nüks darlığın geliştiği ve tedavide en sık balon ve buji dilatasyonunun kullanıldığı gösterilmiştir.

Çalışmamızdaki hastaların ortalama yaşı 32 olarak bulunmuştur. Bu hastaların büyük kısmı çocuk iken kostik madde 
alıp dirençli darlık nedeniyle tedavisi devam eden hastalardır. Hasta yaşı bu nedenle düşük çıkmıştır. Nitekim literatür incelendiğinde kostik hasar ile ilgili çalışmaların çoğunun çocuk hastalar ile yapıldığı görülmektedir (7). Çalışmamızda erkek cinsiyet baskın bulunmuştur. Literatür incelemesinde bizim çalışmamıza benzer şekilde kostik madde içimi ve buna bağlı hasarın erkek cinsiyette baskın olduğu görülmektedir $(8,9)$.

Çalışmamızda özellikle temizlik için kullanılan maddelere bağlı kostik hasar olduğu görülmektedir. Nitekim daha önce yapılan çalışmalar da bunu desteklemektedir (10). Aydın ve ark. kostik madde içen 681 çocukla yaptığı çalışmada da bizim çalışmamızda olduğu gibi çocukların en sık yağ çözücü, çamaşırı suyu (ozon suyu) ve kireç çözücü içtiği görülmektedir (7). Diğer bir çalışmada ise yine çamaşır suyunun (ozon suyu) en sık kostik hasar sebebi olduğu görülmektedir (11). Ülkemiz gibi açıktan temizlik maddelerinin satıldığı ve yeterli güvenlik önlemlerinin alınmadığı ülkelerde bu durum daha sık olarak karşımıza çıkmaktadır.

Çalışmamızda tedavi amaçlı en sık buji ve balon dilatasyonu kullanılmıştır. Balon ve buji dilatasyonu benign özofageal darlıkların esas endoskopik tedavisini teşkil etmektedir. Bu iki yöntemin kıyaslandığı çalışmalarda ise buji dilatasyonu biraz daha etkin olarak bulunmuştur (12). Ancak kostik dişı benign özofageal darlıklarında bu iki yöntemin eşit etkinlikte olduğu düşünülmektedir (13).

Çalışmamıza alınan iki hastamızda lokal steroid enjeksiyonu denenmiş ancak klinik ve endoskopik yanıt alınamamıştır. Gunnarsson'un çalışmasında iki hastaya lokal steroid tedavisi denenmiş ve hastaların fayda gördügü belirtilmiştir ancak bu çalışmada endoskopik bulguların verilmemesi ve hasta sayısının kısıtlı olması nedeniyle bu çalışma yetersiz kalmaktadır (14). Yine başka bir çalışmada benign özofagus darlıklarında lokal steroid enjeksiyonunun faydalı olabileceği belirtilmiş ama tedavi başarısının buji dilatasyonuna göre daha düşük olduğu belirtilmiştir (15). Bir başka çalışmada ise steroid enjeksiyonu buji dilatasyonuna ek olarak yapılmış ve dilatasyon ihtiyacını bir yıla kadar azaltabileceği belirtilmiştir (16). Lokal steroid enjeksiyonunun peptik kaynaklı darlıklarda daha etkili olduğu da akılda tutulmalıdır. Ancak yine de bizim vakamızda olduğu gibi diğer tedavilere dirençli durumlarda tedavide düşünülmelidir.

Çalışmamızda dirençli darlık nedeniyle iki hastaya stent takılmış, sadece bir hastada yanıt alınmıştır. Yakın zamanda yapılmış bir çalışmada kostik kaynaklı özofageal darlığı olan hastalarda tam kaplı stentlerin etkinliği sınırlı bulunmuştur. $\mathrm{Bu}$ hastalarda stentlerin uzun süreli rahatlama için yetersiz olduğu belirtilmiştir (17). Ayrıca yapılan bir diğer çalışmada dilatasyon tedavisi ile karşılaştırıldığında stent tedavisinin, disfajisiz dönemi arttırmada ve dilatasyon sürelerini ve sıkl1ğını azaltmada etkili olmadığı gösterilmiştir (18).

Çalışmamızda 6 hasta opere olmasına rağmen darlık devam etmiş ve endoskopik tedaviye devam edilmiştir. Bu durum da kostik darlıkların çok dirençli olabileceğini göstermektedir. Ayrıca çalışmamızda hastalara ortalama 9 seans işlem yapılmış olmasına rağmen hala tedavilerinin devam etmesi kostik darlıkların çok dirençli olduğunu desteklemektedir. Literatür incelemesinde dirençli kostik özofagus darlıkları ile ilgili çok sayıda çalışma bulunmaktadır. Bu hastalarda standart buji ve balon dilatasyonunun yanında steroid enjeksiyonu, stent uygulaması ve cerrahiye rağmen dirençli darlık durumunun devam ettiği görülmektedir (19).

Çalışmamızın en önemli kısıtlılığı retrospektif olmasına bağlı olarak bilgi eksikliğidir. Ayrıca çalışmamızda endoskopik tedavinin başarısı hastaların tedavisi devam ettiği için tam olarak verilememiştir.

Sonuç olarak kostik madde içimine bağlı özofagus darlı̆̆ benign olmakla birlikte yoğun tedaviye rağmen dirençli bir durumdur. En sik olarak temizlik maddelerinin içimine bağlı olarak gelişmekte, en sık özofagus orta kısmını tutmakta ve tedavide en sık balon ve buji dilatasyon tedavisi kullanılmaktadir.

\section{KAYNAKLAR}

1. Turner A, Robinson P. Respiratory and gastrointestinal complications of caustic ingestion in children. Emerg Med J 2005;22:359-61

2. Gumaste VV, Dave PB. Ingestion of corrosive substances by adults. Am J Gastroenterol 1992;87:1-5

3. Bird JH, Kumar S, Paul C, Ramsden JD. Controversies in the management of caustic ingestion injury: an evidence-based review. Clin Otolaryngol 2017;42:701-8.

4. Ogunrombi AB, Mosaku KS, Onakpoya UU. The impact of psychological illness on outcome of corrosive esophageal injury. Niger J Clin Pract 2013;16:49-53

5. Park KS. Evaluation and Management of caustic injuries from ingestion of acid or alkaline substances. Clin Endosc 2014;47:301-7.

6. Yoon KW, Park MH, Park GS, et al. A clinical study on the upper gastrointestinal tract injury caused by corrosive agent. Korean J Gastrointest Endosc 2001;23:82-7.

7. Aydın E, Özcan R, Emre \$s, ve ark. Çocukluk çağında koroziv madde içimi: Altı yüz seksen bir olgunun değerlendirilmesi. Çocuk Cerrahisi Dergisi 2012;26:26-31.

8. Niedzielski A, Schwartz SG, Partycka-Pietrzyk K, Mielnik-Niedzielska G. Caustic agents ingestion in children: A 51-year retrospective cohort study. Ear Nose Throat J 2019:145561319843109.

9. Dehghani SM, Bahmanyar M, Javaherizadeh H. Caustic ingestion in children in south of Iran: A two-year single center study. Middle East J Dig Dis 2018;10:31-4.

10. Maaloul I, Kmiha S, Yaich S, et al. Epidemiology of home accidents in childhood: experience in the Division of General Pediatrics in Southern Tunisia. Pan Afr Med J 2019;33:108.

11. Aydın C, Açıkalın A, Kozacı N, ve ark. Koroziv Madde Oral Alımı Nedeniyle Başvuran Hastaların Demografik Olarak Değerlendirilmesi. Cukurova Medical Journal 2014;39:271-9. 
12. Dakkak M, Bennett JR. Comparison between Savary Gilliard and balloon dilatation of benign esophageal strictures. World J Surg 1991;15:667.

13. Scolapio JS, Pasha TM, Gostout CJ, et al. A randomized prospective study comparing rigid to balloon dilators for benign esophageal strictures and rings. Gastrointest Endosc 1999;50:13-7.

14. Gunnarsson M. Local corticosteroid treatment of caustic injuries of the esophagus. A preliminary report. Ann Otol Rhinol Laryngol 1999;108:1088-90.

15. De la Garza González SJ, García RG.Update in the endoscopic management of benign esophageal stenoses. Rev Gastroenterol Mex 2005;70:204.
16. Nijhawan S, Udawat HP, Nagar P. Aggressive bougie dilatation and intralesional steroids is effective in refractory benign esophageal strictures secondary to corrosive ingestion. Dis Esophagus 2016;29:1027-31.

17. Kochhar R, Samanta J, Basha J, et al. Biodegradable stents for caustic esophageal strictures: Do they work? Dysphagia 2017;32:575-82.

18. Lu Q, Yan H, Wang Y, et al. The role of endoscopic dilation and stents in refractory benign esophageal strictures: a retrospective analysis. BMC Gastroenterol 2019;19:95.

19. Siersema PD. How to approach a patient with refractory or recurrent benign esophageal stricture. Gastroenterology 2019;156:7-10. 